\title{
Otology
}

\section{Transmeatal microsurgery for intralabyrinthine and intrameatal schwannomas: a reappraisal}

\section{Approccio transmeatale microchirurgico nei neurinomi intralabirintici e intrameatali: rivalutazione di una tecnica}

\author{
Antonio Mazzoni ${ }^{1 *}$, Elisabetta Zanoletti ${ }^{1 *}$, Diego Cazzador ${ }^{1,2}$, Leonardo Calvanese' ${ }^{1}$, Domenico d'Avella ${ }^{3}$, Alessandro Martini ${ }^{1}$ \\ ${ }^{1}$ Otolaryngology Section, Department of Neuroscience DNS, Padova University, Padova, Italy; ${ }^{2}$ Section of Human Anatomy, Department of \\ Neuroscience DNS, Padova University, Padova, Italy; ${ }^{3}$ Academic Neurosurgery, Department of Neuroscience DNS, Padova University, Padova, Italy \\ "A. Mazzoni and E. Zanoletti should be considered joint first authors.
}

\begin{abstract}
SUMMARY
Objective. The interest in surgical routes to the internal auditory canal (IAC) through the external auditory canal for vestibular schwannoma removal has been recently raised by the endoscopic approaches to the lateral skull base. The aim of the study was to reappraise the transmeatal microsurgical approach (TMMa) to the labyrinth and IAC, first described 50 years ago.

Methods. A retrospective series of 8 consecutive patients treated for intralabyrinthine and intrameatal schwannomas through TMMa is presented. Main outcome measures consisted of surgical indications, postoperative complications, facial nerve status, bed mobilisation time, hospitalisation time and tumour recurrence rate.

Results. Surgical indications for TMMa were tumour growth $(62.5 \%)$ and disabling vertigo $(37.5 \%)$ in the present series. Complete tumour removal with no complications and postoperative normal facial nerve function was obtained in all cases. Bed mobilisation occurred after a median of 3 postoperative days (IQR 2.2-3.0) and discharge after a median of 5.6 days (IQR 4.7-7.0). After a median follow-up of 13 months (IQR 7.5-27.5), no tumour recurrence was observed. Conclusions. TMMa indications are limited to schwannomas of the labyrinth and IAC, which dropped out from observation protocols due to unmanageable symptoms or growth. Despite the narrow mini-invasive surgical corridor, the TMMa was a safe an effective microsurgical technique in terms of tumour removal and postoperative course.
\end{abstract}

KEY WORDS: microsurgery, vestibular schwannoma, endaural approach, transmeatal approach, internal auditory canal

\section{RIASSUNTO}

Obiettivo. L'interesse per i corridoi chirurgici dal condotto uditivo esterno al condotto uditivo interno (CUI) nel trattamento del neurinoma è incrementato negli ultimi anni grazie alla divulgazione di approcci endoscopici al basecranio laterale. Lo studio si prefigge di rivalutare l'approccio microscopico transmeatale (TMMa) al labirinto e al CUI, descritto in origine circa 50 anni fa.

Metodi. Otto pazienti sottoposti a TMMa per exeresi di neurinomi intralabirintici o intrameatali sono stati inclusi nello studio. Indicazione chirurgica a TMMa, complicanze postoperatorie, funzionalità del nervo facciale, tempo di mobilizzazione dal letto e di degenza, tasso di recidiva sono state le principali misure di outcome analizzate.

Risultati. Crescita tumorale (62,5\%) e vertigini incoercibili (37,5\%) hanno rappresentato l'indicazione chirurgica più frequente. In tutti i pazienti il tumore è stato rimosso in toto, in assenza di complicanze postoperatorie. La mobilizzazione dal letto è avvenuta dopo 3 giorni (IQR 2,2-3,0), la dimissione dopo 5,6 giorni (IQR 4,7-7,0). All'ultimo follow-up (mediana 13 mesi, IQR 7,5-27,5) non sono state registrate recidive.

Conclusioni. L'indicazione al TMMa è limitata agli schwannomi intralabirintici elo estesi al CUI, che escono dal protocollo di osservazione a causa di sintomi invalidanti o crescita. Nonostante l'accesso chirurgico mini-invasivo offra uno spazio limitato di manovra, il TMMa si è dimostrato una opzione di trattamento microchirurgico sicura ed efficace in termini di rimozione tumorale e decorso postoperatorio.

PAROLE CHIAVE: microchirurgia, schwannoma vestibolare, approccio endocanalare, approccio transmeatale, condotto uditivo interno
Received: April 3, 2020

Accepted: May 18, 2020

Correspondence

Diego Cazzador

Otorhinolaryngology Unit, University of Padova, via Giustiniani 2, 35128 Padova, Italy

Tel. +39049821 8778. Fax +39049821 1994

E-mail: diego.cazzador@unipd.it

Funding

None.

Conflict of interest

The Authors declare no conflict of interest.

How to cite this article: Mazzoni A, Zanoletti E, Cazzador D, et al. Transmeatal microsurgery for intralabyrinthine and intrameatal schwannomas: a reappraisal. Acta Otorhinolaryngol Ital 2020;40:390-395. https://doi. org/10.14639/0392-100X-N0779

() Società Italiana di Otorinolaringoiatria e Chirurgia Cervico-Facciale

\section{(c) (1) $(2)$}

This is an open access article distributed in accordance with the CC-BY-NC-ND (Creative Commons Attribution-NonCommercial-NoDerivatives 4.0 International) license. The article can be used by giving appropriate credit and mentioning the license, but only for non-commercial purposes and only in the original version. For further information: https:// creativecommons.org/licenses/by-nc-nd/4.0/deed.en 


\section{Introduction}

The straight line encompassing external auditory canal, tympanum, labyrinth and internal auditory canal (IAC) is the anatomical premise for the transmeatal approach to the above mentioned sites. The transmeatal route to the labyrinth was used for draining suppurative labyrinthitis and for labyrinthectomy in vertigo ${ }^{1-3}$, and was proposed in 1970 as a microsurgical technique for schwannomas of the IAC, sectioning the vestibular or cochlear nerve or explorationgraft of facial nerve ${ }^{4}$. In 1976, Bochenek ${ }^{5}$ introduced a modification in the approach. The few reports on the transmeatal approach to acoustic schwannoma are reported in Table I ${ }^{4,6-13}$.

The endoscopic surgery of the middle ear recently evolved into the transcanal endoscopic approach to labyrinth and IAC for schwannoma with good outcomes ${ }^{14-16}$.

It is universally acknowledged that the endoscope allows excellent visualisation of structures and hidden sites "around the corner". The endoscopic transcanal approach nevertheless has some drawbacks: 1) the need to create space at the expense of the tympanic bone for placing both instruments and endoscope; 2) the one-hand surgical technique; 3 ) the 2D view.

The transmeatal microsurgical approach (TMMa) was reappraised as an effect of modern imaging and increase in earlydiagnosed small vestibular schwannomas. It underwent rapid development given the promising experiences of the transcanal endoscopic approaches and the expertise gained over the years with conventional microscopic approaches.

Our small series of TMMa is part of a long-lasting experience in the microsurgical management of vestibular schwannoma. Between 1972 and 2019, 2048 cases were treated with different microsurgical approaches. Pure were operated on with conventional approaches, translabyrin-

Table I. Literature on transmeatal microsurgical approach for schwannomas of the labyrinth and/or internal auditory canal.

\begin{tabular}{|c|c|c|}
\hline Author & Year of publication & Number of cases \\
\hline Alvarez De Cozar et al. ${ }^{4}$ & 1970 & 1 \\
\hline Karlan et al. ${ }^{6}$ & 1972 & 1 \\
\hline Wanamaker et al. ${ }^{7}$ & 1972 & 1 \\
\hline Antoli Candela et al. ${ }^{8}$ & 1975 & $5^{\dagger}$ \\
\hline Weimuller et al. ${ }^{9}$ & 1975 & 1 \\
\hline DeLozier et al. ${ }^{10}$ & 1979 & 6 \\
\hline Jiang et al. ${ }^{11}$ & 2011 & 2 \\
\hline Zhu et al. ${ }^{12}$ & 2012 & 1 \\
\hline Mazzoni et al. ${ }^{13}$ & 2017 & $1^{\ddagger}$ \\
\hline
\end{tabular}

the case reported in Alvarez de Cozar et al. ${ }^{4}$ is included.

₹ Included in the present series. thine in 59 , middle cranial fossa in 26 , retrosigmoid in 64 , the two latter with hearing preservation intent. The TMM technique was added to the treatment options since 2015 , with the goal of assessing its potential in itself and in relation to the well documented endoscopic technique ${ }^{14-16}$, as well as defining a mini-invasive surgical corridor to the labyrinth and IAC.

\section{Methods}

\section{Ethical considerations}

The procedures hereby described were in accordance with the ethical standards of the University and the Declaration of Helsinki. Written informed consent was obtained from all patients prior to participation.

\section{Participants}

From 2012 to 2019, 142 patients were diagnosed with intralabyrinthine schwannoma (ILS) or intrameatal vestibular schwannoma. Ninety-seven patients were sent to observation, 45 were submitted to surgical excision. Twenty-one cases $(46.5 \%)$ were operated on with hearing preservation intent, $16(35.5 \%)$ with translabyrinthine approach, eight patients (18.0\%) with ILS and/or intrameatal vestibular schwannoma were operated on via TMMa. The present report focuses on this latter group composed of five ILSs, two intralabyrinthineintrameatal tumours and one pure intrameatal tumour.

\section{Preoperative assessment}

Hearing was evaluated with pure tone and vocal audiometry as pure tone average (PTA) at frequencies 500, 1000, 2000 and $4000 \mathrm{~Hz}$ and word recognition score (WRS) classified according to the American Academy Otolaryngology-Head and Neck Surgery (AAO-HNS) classification ${ }^{17}$. Diagnosis was obtained with contrast enhanced magnetic resonance imaging (MRI) (Fig. 1). High resolution computed tomography

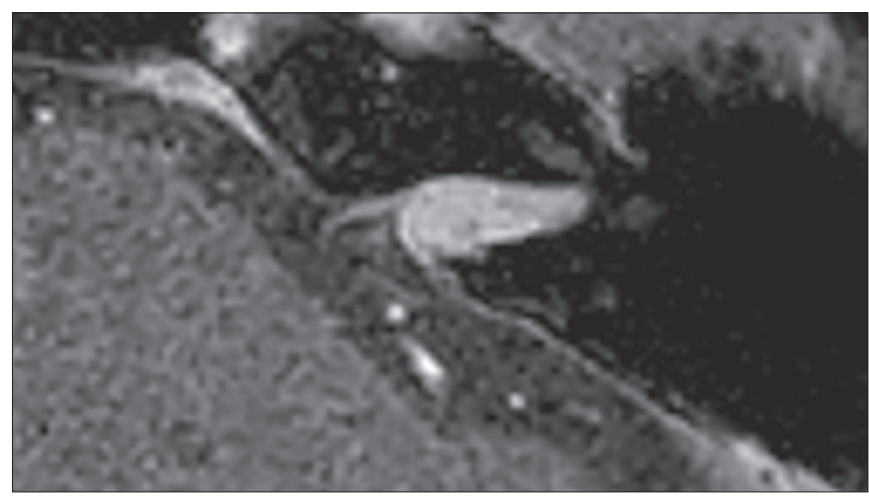

Figure 1. Contrast enhanced T1-weighted MRI of an intrameatal tumour, left side. The facial quadrant of the fundus is free from tumour. 
(HRCT) was indicated for surgical planning and immediate postoperative evaluation (Fig. 2d). Facial nerve status was evaluated with the House-Brackmann (HB) grading system ${ }^{18}$. Indications to TMMa included ILS and intrameatal vestibular schwannomas, hearing class D according to the AAOHNS, unmanageable vertigo and/or tumour growth at serial imaging. Hearing preservation or rehabilitation were not considered.

\section{Surgical technique}

The patient is lying supine with the head turned to the opposite side; surgery is performed with general endotracheal anaesthesia and continuous facial nerve monitoring.

1. After the endoaural incision, the tympano-malleo-meatal flap is harvested with circumferential (from 10 to $2 \mathrm{o}$ 'clock) and longitudinal incisions. Malleus neck and tensor tympani tendon are sectioned. The complex of skin-drum-malleus handle is raised against the anterior wall of the canal. If the anterior wall is to be drilled, the flap is raised further up and placed against the cartilaginous wall.

2. Enlarging the ear canal. The outer ear canal is enlarged by drilling of its bony walls as much as required by the anatomy of the canal and by the access either to labyrinth or IAC, the latter requiring a larger access. The walls are not removed in full thickness, as they need to accommodate the repositioned tympanomeatal flap at the end of the procedure. The bony tympanic annulus is removed for

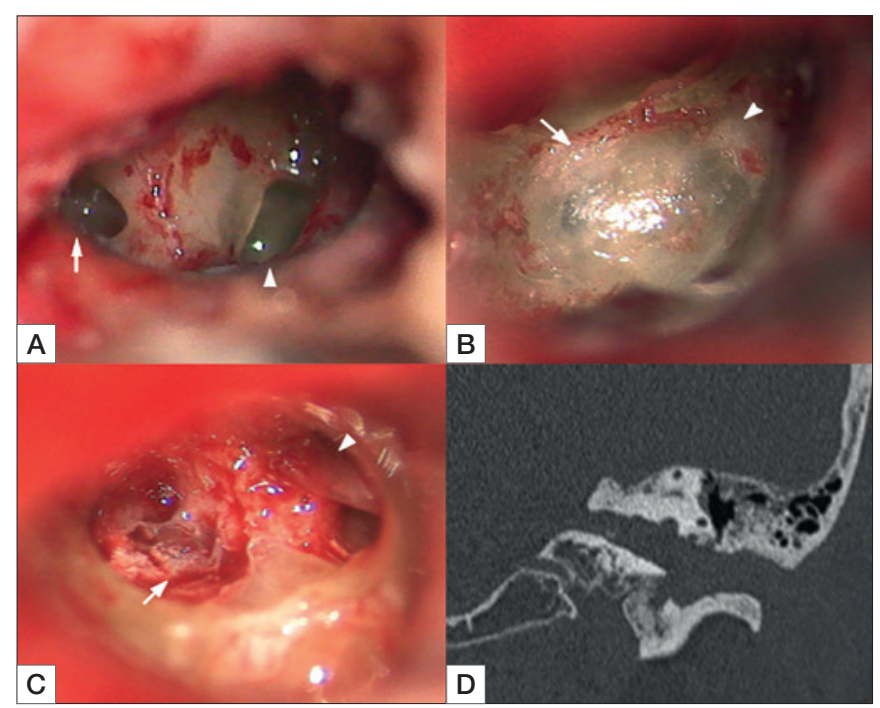

Figure 2. Transmeatal microsurgical approach, intraoperative pictures: A) round window (arrow) and oval window (arrowhead) after removal of ossicles; B) medial wall of vestibule with the whitish foramina of saccular (arrow) and utricular nerves (arrowhead); C) the tumour is visible in the internal auditory canal (arrow), the facial nerve exits from the Fallopius (arrowhead). D) Left side, postoperative coronal CT scan showing the surgical corridor from the external to the internal auditory canal. usually $2 \mathrm{~mm}$ but on the anterior wall, where it remains intact.

3. Vestibulo-cochleostomy. This is sufficient for intrameatal tumour, it is a step for the exposure of IAC. After footplate removal, the promontory is drilled between the oval and round window (Fig. 2a), and further anteriorly to open the cochlea basal and second turns, the access to vestibule is enlarged. The medial wall shows the whitish dot of the saccular nerve entry. For ILSs, the vestibulocochleostomy is extended to the sites occupied by tumour itself. In tumours of the vestibule only, it is not necessary to drill out the cochlea. After carefully drilling the bone between the upper margin of the oval window and the Fallopius, and redirecting cranially the scope, the dot of the superior vestibular nerve entry comes under view. The latter dot is the landmark leading to the superior vestibular nerve to facial nerve and Fallopius entry (Fig. 2b).

4. Exposure of IAC. The medial wall is thinned out with drilling first around the saccule dot, thereon the utricular dot (Fig. $2 \mathrm{~b}$ ), being here cautious as the facial nerve lies just deep to the superior vestibular nerve. The crista trasversalis, emerging in the drilled bed, is a landmark leading the bone removal to completely open the fundus. Following the full exposure of the fundus, the facial nerve entering the labyrinthine portion of the Fallopius can be appreciated (Fig. 2c). The canal can be exposed up to the porus by drilling first along the floor and thereon extending to the complete posterior wall.

5. Tumour removal. After opening the dura, displacing the tumour gives way to a moderate outflow of CSF. The main step here is to follow the interface between the tumour and the facial nerve at the fundus and Fallopius orifice, thereon proximally. The CSF pressure let the tumour herniate and favours grasping it with suction or instruments, allowing its piecemeal or en-bloc removal (Fig. 3). The cochlear nerve lies at the inferior-anterior wall of the canal. The flattened facial nerve is seen lying almost vertically at the anterior or anterosuperior wall held by arachnoid at the porus and floating on, and pushed outward by the CSF (Fig. 4a, b). A piece of fat is placed to seal the IAC and labyrinth; the Eustachian tube is closed with muscle and fat obliterates the tympanum. The drum is repositioned, and the external auditory canal is packed. CSF leak was to be ruled out at day $5^{\text {th }}$, facial nerve function was evaluated at day $1^{\text {st }}$ and day $5^{\text {th }}$, then at one, 6 and 12 months after surgery. Vertigo, dizziness, imbalance, pain or other symptoms were recorded. Contrast enhanced MRI was planned at one month, then 1-3-5-10 years.

\section{Results}

Patient characteristics are summarised in Table II. At presentation, severe to profound hearing loss was the most reported 


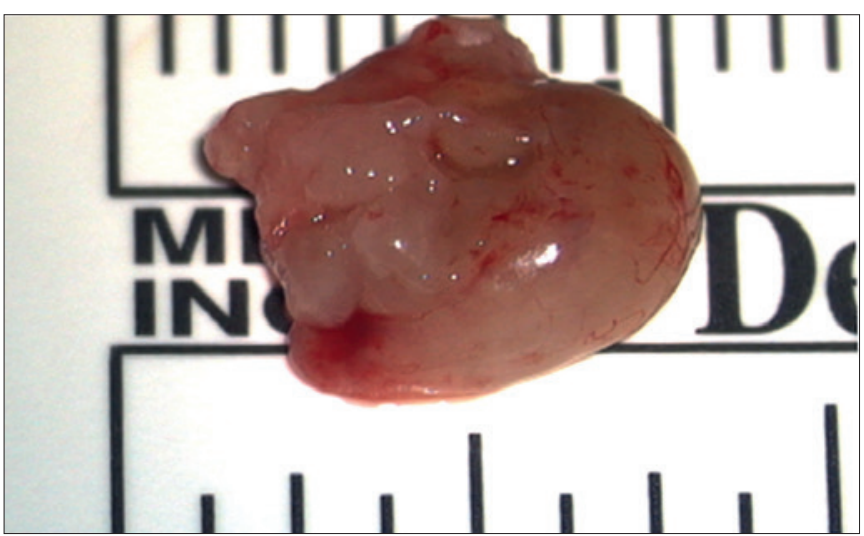

Figure 3. Intraoperative specimen of a $10-\mathrm{mm}$ intrameatal tumour. The proximal end is the round surface on the right pole of the tumour. Irregular tumour borders are due to surgical manoeuvres.

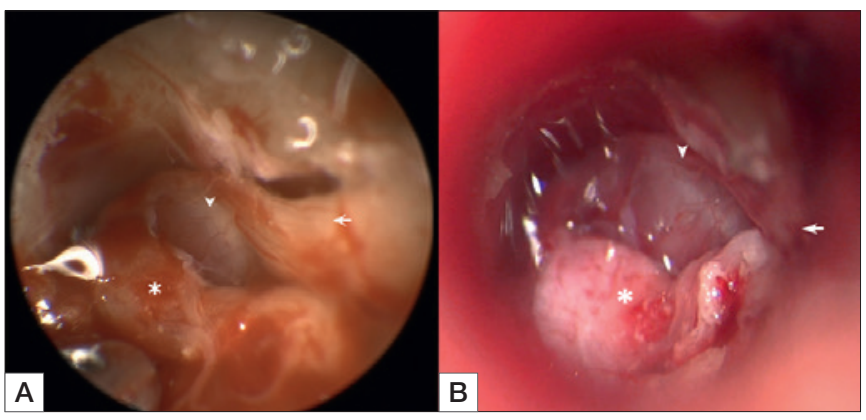

Figure 4. Intraoperative view at the end of the transmeatal microsurgical approach, after tumour removal. A) Endoscopic view with $0^{\circ}$ endoscope; B) microscopic view. *: dura of the petrous posterior wall; arrow: entrance of the facial nerve into the Fallopius canal; arrowhead: facial nerve.

symptom $(87.5 \%)$, followed by tinnitus $(50.0 \%)$, vertigo $(25.0 \%)$ and auricular fullness (12.5\%). Prior to surgical removal, five patients had been enrolled in a wait and scan policy for a median of 61 months (IQR 31.5-136.0). During observation, four of five patients (80\%) showed tumour growth at serial MRIs. The only patient with serviceable hearing at diagnosis went through progressive hearing loss to class D.

Indications for surgical treatment were tumour growth for five patients $(62.5 \%)$ and disabling vertigo for three $(37.5 \%)$. There were no postoperative complications. Postoperative facial nerve status at day one and at last follow-up was grade I HB for all the patients. None required postoperative ICU admission. One patient experienced vertigo for few days. Patient mobilisation was performed after a median time of 3 postoperative days (IQR 2.2-3.0). Patients were discharged after a median time of 5.6 days (IQR 4.77.0). At last follow-up (median 13 months; IQR 7.5-27.5 months), no tumour recurrence was observed. All patients presented a well-healed tympanic membrane.

\section{Discussion}

The traditional approaches to the IAC and labyrinth, namely the microsurgical middle cranial fossa and translabyrinthine with the extensions to the cochlea, are now faced by surgical corridors through the external auditory canal, i.e. the purely endoscopic transcanal and microsurgical transmeatal approaches. Although proposed in recent years with the exclusive use of the endoscope ${ }^{14-16}$, a transcanal approach to the IAC was already described in 1970, when Alvarez De Cozar reported on the "... transvestibular approach to the IAC, aiming at the surgery of the acoustic neuroma presents the following anatomical limits: anteriorly, the carotid canal and Eustachian tube; posteriorly, the vertical Fallopius: inferiorly, the hypotympanum and the jugular bulb; superiorly, the tympanic portion of the facial nerve." The authors added that "... The sacrifice of vestibule and cochlea provides a surgical field wide enough to remove an acoustic neuroma of one $\mathrm{cm}$ or less (...) and allows to drop the transtemporal approach as a route to access the IAC" ${ }^{4}$. In 1975, the same group reported their experience with the transvestibular approach to the IAC on 178 otoneurological cases, including 5 vestibular schwannomas ${ }^{8}$. At those times, the diagnosis of millimetric tumours was still to come, literature studies were sparse and mostly involved single case reports on intrameatal schwannomas removed through a transmeatal-transvestibular approach (Tab. I).

Currently, intrameatal tumours are frequently diagnosed and intralabyrinthine lesions are not an exceptional finding anymore. In our series of patients who underwent surgery via the TMMa for the treatment of intrameatal and intralabyrinthine schwannomas, the approach allowed direct access to the labyrinth and the IAC fundus with complete tumour removal in all cases. Surgical indications for TMMa included ILS or/and intrameatal vestibular schwannomas with AAO-HNS hearing class D, unmanageable vertigo, or tumour growth at serial imaging.

The reappraisal of the TMMa at present might confer excellent outcomes with minimum surgical morbidity, as well as short hospital stay. TMMa allows to perform a straightforward surgical corridor to the IAC. The two-hands dissection microsurgical technique involves improved ergonomics, which is a fundamental requisite for adequate handling of adherences tumour/facial nerve, as well as tumour/vascular loops ${ }^{20}$. There is no inherent morbidity of the surgical access due to sacrifice of the external auditory canal.

As such, the technical highlights of TMMa included endoaural skin incision of the external auditory canal, tympano-malleo-meatal flap that fully opened the lumen of the canal to view and instruments, and limited removal of the 
Table II. Clinical characteristics of patients underwent transmeatal microsurgical approach for schwannomas of the labyrinth and internal auditory canal.

\begin{tabular}{|c|c|c|c|c|c|c|c|c|c|}
\hline Patients & Age & Sex & $\begin{array}{c}\text { Initial } \\
\text { observation }\end{array}$ & Extension $\S$ & $\begin{array}{c}\text { IAC } \\
\text { involvement }\end{array}$ & $\begin{array}{l}\text { Decision for } \\
\text { surgery }\end{array}$ & Complications & $\begin{array}{l}\text { Hospitalisation } \\
\text { (days) }\end{array}$ & $\begin{array}{l}\text { Follow-up } \\
\text { (months) }\end{array}$ \\
\hline 1 & 76 & M & Y & IVC & $\mathrm{N}$ & Growth & $\mathrm{N}$ & 3 & 17 \\
\hline 2 & 59 & $\mathrm{~F}$ & Y & IC & $\mathrm{N}$ & Growth & $\mathrm{N}$ & 4 & 35 \\
\hline 3 & 37 & $\mathrm{~F}$ & Y & IV & $\mathrm{N}$ & Growth & $\mathrm{N}$ & 5 & 34 \\
\hline 4 & 48 & $\mathrm{~F}$ & Y & TLAB & Y & Growth + symptoms & $\mathrm{N}$ & 7 & 21 \\
\hline 5 & 44 & M & $\mathrm{N}$ & IVC & N & Symptoms & $\mathrm{N}$ & 5 & 8 \\
\hline 6 & 48 & $\mathrm{~F}$ & Y & IC & N & Symptoms & Vertigo & 9 & 9 \\
\hline 7 & 38 & $M$ & $\mathrm{~N}$ & TMOD & Y & Growth & $\mathrm{N}$ & 7 & 6 \\
\hline 8 & 76 & $\mathrm{~F}$ & $\mathrm{~N}$ & $\mathrm{IAC}$ & Y & Symptoms & $\mathrm{N}$ & 5 & 6 \\
\hline
\end{tabular}

M: male; F: female; Y: yes; N: no; ${ }^{\S}$ according to the Modified Kennedy Classification ${ }^{19}$; IVC: intravestibulocochlear; IC: intracochlear; IV; intravestibular; TLAB: translabyrinthine; TMOD: transmodiolar; IAC: internal auditory canal.

tympanic annulus and tympanic bone, that allowed repositioning of the tympanic membrane. Unfavourable size and shape of the canal conditioned its enlargement, but did not require its suture. The next steps of the approach involved the drill out of promontory, cochlea, vestibule medial wall with the familiar landmarks of the saccule and utricle dots leading to the vestibular nerves at the fundus, and the posterior-inferior wall of the IAC. If compared to the traditional lateral approach, the small outflow of CSF is characteristic of the transcanal/transmeatal approaches and may be due to the short time of dural opening, and possibly to the arachnoid folds in the IAC. As a consequence of CSF sparing, there are less brain collapse, less chances of pneumocephalus and fast recovery.

Further considerations on TMMa concern the possibility of hearing rehabilitation with cochlear implant. This requires preserving the cochlear nerve and cochlea, or the full labyrinth ${ }^{21}$ or carefully evaluating if the remains of the opened cochlea and spiral ganglion are suitable to implant ${ }^{22}$. Whether an open cochlea would house a cochlear implant with successful long-term outcomes is still a matter of debate.

Our conclusions on this preliminary experience with TM$\mathrm{Ma}$, despite the small number of the present series, rely upon our experience with over 2000 conventional approaches and can be seen in the context of current management of small vestibular schwannomas ${ }^{21}$. The applicability of the TMMa recognised for tumours of the labyrinth and/or internal auditory canal. The AICA looping inside the canal may represent a caveat in favour of a safe translabyrinthine approach.

\section{Conclusions}

Transcanal or transmeatal approaches, either microsurgical or endoscopic, have rare indication for tumours of labyrinth and/or IAC, the majority of whom are submitted to obser- vation. The goal is the removal of tumour with no surgical morbidity, as it is postulated by the small benign lesion, as well as by the results of the alternative, conventional operations. Approaches through the external auditory canal are purported to having the advantage of a direct and quick route, which could appear to be progress over the conventional approaches. This theory seems to be supported by the initial experience and deserves further trial. Of the current endoscopic and microscopic approaches, the latter may be a step forward as effect of the microsurgical technique and safer handling of unexpected difficulties.

\section{Acknowledgements}

The authors thank Frances Coburn for the English revision of the paper.

\section{References}

1 Schuknecht NF. Ablation therapy in the management of Ménière's disease. Acta Otolaryngol Suppl 1957;132:1-42.

2 Jongkees LBW. Chirurgie des Mastoids und der Pyramidenspitze sowie des intratemporalen Nervus facialis. In: Naumann HH, editor. (Hrsg) Kopf und hals Chirurgie (Bd.1). Stuttgart: Thieme Verlag; 1976. p. 168.

3 Glasscock ME III, Shambaugh GE. Surgery of the ear. Philadelphia: Saunders; 1990. p. 492.

4 Alvarez De Cozar F, Antoli Candela F. Chirurgie transvestibulaire. Rev Laryngol Otol Rhinol 1970;91:927-35.

5 Bochenek Z, Kukwa A. Die Transtympanale Neurektomie des Nervus Vestibulo-cochlearis. HNO 1976;24:197-9.

6 Karlan MS, Basek M, Potter GB. Intracochlear neurilemmoma. Arch Otolaryngol 1972;96:573-5.

7 Wanamaker HH. Acoustic neuroma primary arising in the vestibule. Laryngoscope 1972;82-1040-4. https://doi.org/10.1288/00005537197206000-00013

8 Antoli Candela F Jr, Alvarez de Cozar F, Antoli Candela F. Transvestibular approach to the internal auditory canal. Ann Otol Rhinol Laryngol 1975;84:145-51. https://doi. org/10.1177/000348947508400201 
9 Weimuller EA Jr. Unsuspected vestibular schwannoma. Arch Otolaryngol 1975;101:630-2. https://doi.org/10.1001/archotol.1975.00780390044012

10 DeLozier HL, Gacek RR, Dana ST. Intralabyrinthine schwannoma. Ann Otol Rhinol Laryngol 1979;88:187-91. https://doi. org/10.1177/000348947908800207

11 Jiang ZY, Kutz JW Jr, Roland PS, et al. Intracochlear schwannoma confined to the otic capsule. Otol Neurotol 2011;32:117-9. https://doi. org/10.1097/MAO.0b013e31822a20ea

12 Zhu AF, McKinnon BJ. Transcanal surgical excision of an intracochlear schwannoma. Am J Otolaryngol 2012;33:779-81. https://doi. org/10.1016/j.amjoto.2012.07.007

13 Mazzoni A, Zanoletti E, Faccioli C, et al. Acoustic schwannoma with intracochlear extension and primary intracochlear schwannoma: removal through translabyrinthine approach with facial bridge cochleostomy and transcanal approach. Eur Arch Otorhinolaryngol 2017;274:2149-54. https://doi.org/10.1007/s00405017-4501-3

14 Marchioni D, Alicandri-Ciufelli M, Rubini A, et al. Exclusive endoscopic transcanal transpromontorial approach: a new perspective for internal auditory canal schwannoma. J Neurosurg 2017;126:98-105. https://doi.org/10.3171/2015.11.JNS15952

15 Marchioni D, Carner M, Soloperto D, et al. Expanded transcanal transpromomtorial approach: a novel surgical technique for cerebellopontine angle vestibular schwannoma removal. Otolaryngol Head Neck Surg 2018;158:710-5. https://doi. org/10.1177/0194599818756592
16 Marchioni D, Soloperto D, Masotto D, et al. Transcanal transpromontorial acoustic neuroma surgery. Results and facial nerve outcomes. Otol Neurotol 2018;39:242-9. https://doi.org/10.1097/ MAO.0000000000001658

17 Committee on Hearing and Equilibrium guidelines for the evaluation of hearing preservation in acoustic neuroma (vestibular schwannoma). American Academy of Otolaryngology-Head and Neck Surgery Foundation, INC Otolaryngol Head Neck Surg 1995;113:179-80. https://doi.org/10.1016/S0194-5998(95)70101-X

18 House JW, Brackmann DE. Facial nerve grading system. Otolaryngol Head Neck Surg 1985;93:146-7. https://doi. org/10.1177/019459988509300202

19 Van Abel KM, Carlson ML, Link MJ, et al. Primary inner ear schwannomas: a case series and systematic review of the literature. Laryngoscope 2013;123:1957-66. https://doi.org/10.1002/lary.23928

20 Mazzoni A, Hansen CC. Surgical anatomy of the arteries of the in ternal auditory canal. Arch Otolaryngol 1970;91:128-35. https://doi org/10.1001/archotol.1970.00770040198005

21 Zanoletti E, Mazzoni A, Martini A, et al. Surgery of the lateral skull base: a 50-year endeavor. Acta Otorhinolaryngol Ital 2019;39(Suppl.1):S1S146. https://doi.org/10.14639/0392-100X-suppl.1-39-2019

22 Choudhury B, Carlson M, Jethamanest D. Intralabyrinthine schwannoma: disease presentation, tumor management, and hearing rehabilitation . J Neurolog Surg B 2019;80:196-202. https://doi. org/10.1055/s-0039-1678731 